\section{Study on endocrine disruptors levels in raw milk from cow's farms: Risk assessment}

\author{
Serena Santonicola, ${ }^{1}$ \\ Maria Carmela Ferrante, ${ }^{1}$ \\ Genni di Leo, ${ }^{2}$ Nicoletta Murru, ${ }^{1}$ \\ Aniello Anastasio, ${ }^{1}$ \\ Raffaelina Mercogliano ${ }^{1}$
}

${ }^{1}$ Department of Veterinary Medicine and Animal Production, University of Naples; ${ }^{2}$ Private Veterinary Practitioner, Naples, Italy

\section{Abstract}

Diet represents the primary route for human exposure to bisphenol A (BPA). As endocrine disruptor (ED), BPA has raised concerns about its adverse effects on human health. Therefore, EFSA recommended a tolerable daily intake (t-TDI) of $4 \mu \mathrm{g} / \mathrm{kg}$ bw/day and the EU Regulation n. 2018/213 fixed a specific migration limit (SML) of $0.05 \mathrm{mg} / \mathrm{kg}$ for BPA in food from plastic materials intended to come in contact with food. BPA could be present in milk due to environmental contamination, and also as a result of the migration from contact materials used during milking and storage. Considering the widespread consumption of milk and milk products, the contamination of dairy products is a matter of public health concern. The aim of the study was to investigate the BPA contamination levels of raw cow's milk from two farms located in Campania region, Italy. The milk samples $(n=22)$, weekly collected from the cooling tank, were analyzed using liquid chromatography with fluorescence detection. In raw milk from both farms, preliminary results showed the occurrence of BPA levels lower than the SML limit, ranging from not detected to $2.34 \mu \mathrm{g} / \mathrm{L}$. The consumer exposure, calculated considering a hypothetical raw milk consumption and three possible scenarios, was below the t-TDI. Despite the low levels of exposure through milk consumption, low doses can have lasting effects during human development. Thus, new approaches, methods, and plans should be applied to monitor ED contamination, such as BPA and other pollutants, and to assure milk safety.

\section{Introduction}

Many chemical compounds, recognized as endocrine disruptors (EDs), are capable of mimicking the effect of natural hor- mones, interacting with their receptors and inducing the activation of the same physiological pathways in the living organisms (US EPA, 2000). The environmental presence of EDs is mainly linked to anthropogenic activities, and the diet represents the primary route for human exposure. Complex mixtures of EDs can enter the food chain and accumulate in living organisms higher up the food chain such as humans (Diamanti-Kandarakis et al., 2009).

Among the different ED compounds, Bisphenol A (BPA), 2,2-bis(4-hydroxyphenyl) propane, is an industrial chemical widely used in food packaging (Tzatzarakis et al., 2017). BPA tends to migrate from can containers into foods, especially at elevated temperatures, and may be detected in human biological matrices, including serum, urine, amniotic fluid, follicular fluid, placental tissue, breast milk and umbilical cord blood (Cirillo et al., 2015; EFSA 2015; Siddique et al., 2016). It is able to interfere with the endocrine system inducing negative impacts on sexual development, growth, stress response, insulin production, sexually dimorphic behavior, reproduction and fetal development, and immune functions (Cirillo et al., 2015; Legler et al., 2015; Bansal et al., 2018). Therefore, a temporary tolerable daily intake (t-TDI) of 4 $\mu \mathrm{g} / \mathrm{kg}$ bw/day was recommended for BPA by EFSA. In addition, the EU Regulation No. 2018/213 fixed a specific migration limit (SML) of $0.05 \mathrm{mg} / \mathrm{kg}$ in food from plastic materials intended to come in contact with food, while the EU Regulation No. $321 / 2011$ imposed not to use BPA in the manufacture of baby bottles (European Commission, 2011; EFSA, 2015; European Commission, 2018). As chemical hazard, BPA may enter the dairy supply chain through various sources, as environmental contamination, uptake, and accumulation by animals (Grumetto et al., 2013). Being fat-soluble, it may be stored in adipose tissue, secreted in cow's milk fat and accumulated in fat dairy products (Georgescu and Georgescu, 2013). In addition, BPA may be introduced in milk at the farm during milking from plastic parts of the milking machines, through the transfer from bulk milk to storage tanks, or also at the dairy company during thermal treatments and packaging. In fact, the diffusion coefficient of plastic components increases as temperature increases, and the BPA migration tends to increase when extreme temperature fluctuations (for example, from freezer temperatures to ultra-high temperatures) occur during the milk treatments (Tehrany and Desobry, 2004; Danaher and Jordan, 2013; Galloway, 2015; Mercogliano and Santonicola, 2018).
Correspondence: Serena Santonicola, Department of Veterinary Medicine and Animal Production, University of Naples "Federico II", 80137 Naples, Italy.

E-mail: serena.santonicola@unina.it

Key words: Raw milk, Bisphenol A, Risk assessment

Contributions: the authors contributed equally.

Conflict of interest: the authors declare no potential conflict of interest.

Funding: none

Received for publication: 3 July 2018 . Revision received: 12 October 2018.

Accepted for publication: 16 October 2018.

This work is licensed under a Creative Commons Attribution-NonCommercial 4.0 International License (CC BY-NC 4.0).

CC Copyright S. Santonicola et al., 2018

Licensee PAGEPress, Italy

Italian Journal of Food Safety 2018; 7:7668

doi:10.4081/ijfs.2018.7668

Considering the widespread consumption of milk products by infants, children, and adults, the occurrence of quantifiable levels of BPA represents a matter of public health concern (Niu et al, 2017). Several studies reported the occurrence of BPA levels in dietary milk, but data on the occurrence in raw milk at the farm are scarce, and further information on the contamination pathways in milk is needed (EFSA 2015). The aim of the research was: i) to study the occurrence of BPA, as ED, in raw milk, and ii) to evaluate the risk assessment considering different scenarios of dietary exposure through a hypothetical consumption of raw milk at the farm.

\section{Materials and Methods}

\section{Reagents and materials}

BPA standard (minimum purity of $99 \%$ ) was purchased from Sigma-Aldrich (Dorset, UK). Methanol (for high-performance liquid chromatography, HPLC), acetonitrile (for HPLC), and water plus (for HPLC) were provided by Carlo Erba (Milan, Italy). The SPE cartridge (Chromabond C18, Macherey-Nagel, Duran, Germany) were purchased from Delchimica (Naples, Italy).

Stock solution $(0.1 \mathrm{mg} / \mathrm{mL})$ of BPA was prepared in acetonitrile, as solvent, and stored at $4^{\circ} \mathrm{C}$. The analyses were carried out 
using a Jasco HPLC apparatus equipped with a $20-\mu \mathrm{L}$ loop, and a Jasco quaternary pump 2089 plus, combined with a Jasco fluorescence detector $821-F p$ (HPLC/FD). A Synergi column $4 \mu \mathrm{m}$ Fusion-RP $80 \AA$ (250 by $4.60 \mathrm{~mm}$ inside diameter; Phenomenex, Torrance, CA) was used.

\section{Sample collection}

Two cow farms indicated as A and B and located in Irpinia, a district of the Apennine Mountains in Campania region (Italy), participated in this survey. Irpinia is a territory largely mountainous with valleys where environmental-friendly agriculture is promoted. The farms were chosen with fields $>30 \mathrm{~km}$ away from any major source of contamination. During summer, the cows Brown Swiss (n.77 of farm A and n.67 of farm B; average 5 years old; producing milk with fat content of $4.5 \%$ ) were grazing outside in pastures, while at night and during winter inside the stables. The milking process occurred mechanically twice a day in the stables, and every 2-3 days the cooling tank of the farms was emptied by a milk collecting company that delivered the milk to the dairy factories. A total number of 22 raw milk samples was weekly collected in glass containers from the cooling tank of each farm, and then refrigerated at $\pm 4^{\circ} \mathrm{C}$ until the time of analysis.

\section{BPA analysis in raw milk}

The sample preparation was performed, according to Grumetto et al. (2013), by adding $2.5 \mathrm{~mL}$ of milk to $7.5 \mathrm{~mL}$ of deionized water. Then this mixture was sonicated for 30 minutes at room temperature in an ultrasonic apparatus $(40 \mathrm{kHz}$; Branson ultrasonic 2210, Branson Ultrasonics, Danbury, CT), and loaded into an SPE cartridge, previously conditioned with $10.0 \mathrm{~mL}$ of acetonitrile and equilibrated with 10.0 $\mathrm{mL}$ of deionized water. The cartridges were then washed with $20.0 \mathrm{~mL}$ of water, and two different solutions of water and methanol (80:20 and 60:40, vol/vol) under vacuum. Finally, the BPA retained in the cartridge was eluted with $10.0 \mathrm{~mL}$ of acetonitrile, and the eluate was collected in an amber vial before the HPLC analysis. Each sample was analyzed in duplicate.

\section{Instrumental parameters}

BPA detection was performed through HPLC/FD. The mobile phase consisted of acetonitrile-water $(70: 30, \mathrm{vol} / \mathrm{vol})$, and the flow rate was set at $0.9 \mathrm{~mL} / \mathrm{min}$ (isocratic run). The fluorometric detection was carried out at an excitation wavelength of $273 \mathrm{~nm}$ and an emission wavelength of $300 \mathrm{~nm}$.

BPA was identified based on retention time, and the quantification was performed using an external standard method. A calibration curve was obtained by injecting standard solutions of BPA at concentrations in a range of $0.03-100 \mu \mathrm{g} / \mathrm{L}$. The LOD and the LOQ were 0.01 and $0.03 \mu \mathrm{g} / \mathrm{kg}$, respectively. The correlation coefficient (r) between peak area and BPA concentrations was 0.9969 .

\section{BPA daily intake assessment}

In order to evaluate the potential risks related to the occurrence of BPA levels detected at farms A and B, in our study a hypothetical consumption of raw milk collected from the cooling tank was considered.

According to Cirillo et al. (2015), BPA daily intake was evaluated considering a low $(100 \mathrm{~mL} / \mathrm{die})$, and high milk consumption $(500 \mathrm{~mL} / \mathrm{die})$, based on the average milk consumption (200 $\mathrm{mL} / \mathrm{die})$ for an Italian consumer (Piccinelli et al., 2011). These data were correlated to BPA levels detected in raw milk samples. Three possible exposure scenarios were considered: a best case (minimum BPA concentration), a medium case (average BPA concentrations), and a worst case (maximum BPA concentration). To measure the BPA daily intake ( $\mu \mathrm{g} / \mathrm{kg}$ bw/day) the following formula was applied (Cirillo et al., 2015):

Daily intake $=\frac{C * d I R}{b w}$ where $C$ is the BPA concentration (minimum, maximum and mean concentrations) $(\mu \mathrm{g} / \mathrm{Kg})$ found across sample units of analyzed raw cow's milk, $d I R$ (daily Ingestion Rate) is the daily consumption of milk (low, high and mean consumption), while $b w$ is the corresponding average body weight $(\mathrm{Kg}$ 62) of Italian consumers.

\section{Results}

\section{BPA concentrations in raw milk}

Except for one sample from farm A, quantifiable BPA levels, below the SML value, were detected in raw milk samples at the farms (Table 1).

\section{BPA daily intake}

The levels of exposure through the consumption of the raw milk samples showed a BPA daily intake below the t-TDI (Table 2).

\section{Discussion}

\section{BPA contamination of raw milk}

The study showed the occurrence of quantifiable BPA levels in raw cow's milk from two farms located in Campania region. To the best of our knowledge, there was not any similar study on the BPA levels in raw cow's milk at the farm (Mercogliano and Santonicola, 2018).

The cow's exposure through the environmental sources and the ingestion of polluted feed could be potential contamination pathways inducing the BPA excretion through the milk (Carnevali et al., 2017). Lower BPA concentrations were detected in raw milk from farm A than farm B. This finding suggests that, as environmental

Table 1. Concentrations of BPA (min-max and mean values) in raw milk.

\begin{tabular}{lccc} 
& $\begin{array}{c}\text { Nilk samples from } \\
\text { the cooling tank, } N\end{array}$ & Range, $\mu g / L$ \\
Farm A & 11 & ND-1.465 & \\
Farm B & 11 & $0.032-2.340$ & 0.685 \\
\hline
\end{tabular}

Table 2. BPA daily intake based on the daily milk consumption and contamination levels of raw milk.

\begin{tabular}{|c|c|c|c|c|}
\hline \multirow{2}{*}{\multicolumn{2}{|c|}{$\begin{array}{l}\text { Daily milk consumption } \\
\qquad \begin{array}{l}\text { Best case: } \\
\text { Minimum BPA concentration }\end{array}\end{array}$}} & \multicolumn{2}{|c|}{$\begin{array}{l}\text { BPA concentrations } \\
\text { Medium case: } \\
\text { Mean BPA concentrations }\end{array}$} & \multirow[t]{2}{*}{$\begin{array}{l}\text { Worst case: } \\
\text { Maximum BPA concentration }\end{array}$} \\
\hline & & & & \\
\hline Low (100 mL/die) & 0.00003 & 0.001 & 0.0014 & 0.003 \\
\hline Mean $(200 \mathrm{~mL} / \mathrm{die})$ & 0.0002 & 0.002 & 0.0028 & 0.007 \\
\hline High (500 mL/die) & 0.001 & 0.005 & 0.007 & 0.018 \\
\hline
\end{tabular}


source, the geographic area, where the milk was produced, was characterized by low levels of contamination, and may not have played an important role in the BPA levels along the milk chain. According to Cirillo et al. (2015), BPA migration from plasticized contact materials (e.g. milk tubes, and sealants used in the milking machine) and from the contact materials of the cooling tank may have contributed to contamination levels detected in raw milk from both farms. In particular, rubber and PVC milk tube (short milk, air, and pulse tubes) and other plastic accessories (e.g. pulsators) were used as components of milking machine and milk delivery lines of the two farms. Therefore, the mechanical milking and the transfer of milk in the cooling tank might be identified as contamination sources (Danaher and Jordan, 2013; Chege and Ndungu, 2016).

Variable BPA contamination levels may be detected in raw, commercial milk and cheese. Bibliographic data reported higher BPA levels in commercial milk (0.38-5.47 $\mu \mathrm{g} / \mathrm{kg}$, and $14.0-521.0 \mu \mathrm{g} / \mathrm{kg}$ ) and cheese $(2.24 \mu \mathrm{g} / \mathrm{kg})$ (Molina-Garcìa et al., 2012; Grumetto et al., 2013; Wlodarczyk, 2015) than those detected in our study in raw milk. The different contamination levels in raw, commercial milk and cheese could be related to factors, such as the quality of the materials in contact with milk during production at the farm, and the treatment conditions and packaging materials used at the dairy company (Liu et al., 2008; Grumetto et al., 2013). These data suggest that the contamination levels of raw milk could further change during production and packaging of the commercial milk.

The occurrence of BPA in a widely consumed food such as milk represents a food safety concern, also at low levels (Muncke, 2009; Kolatorova et al., 2017). Therefore, to promote dairy safety, monitoring programs risk-based and focused on the most relevant chemical hazards, including EDs, should be applied into the milk chain

\section{Farm A: Medium case}

\author{
$\mathrm{A}>0.137 \mu \mathrm{g} / 200 \mathrm{~mL} \quad \mathrm{~A}<0.137 \mu \mathrm{g} / 200 \mathrm{~mL}$
}

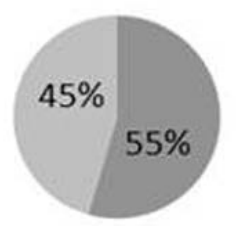

(Santonicola and Mercogliano, 2016; European Commission, 2017; Santonicola et al., 2017a; Santonicola et al., 2017b; van Asselt et al., 2017).

\section{BPA human exposure}

Although EDs may be absorbed through inhalation and dermal exposure, one consistent source of exposure is represented by the consumption of contaminated food (Carnevali et al., 2017). Adults may be affected mostly through the consumption of canned food $(50 \%)$, while infants through the infant formula consumption (25-37\%) (Bemrah et al., 2014; EFSA, 2015).

A comprehensive and quantitative risk assessment involves the evaluation of the daily consumption of food and the levels of the contaminant. In our study, the risk assessment based on a hypothetical consumption of raw milk from the cooling tank showed exposure levels below the t-TDI (EFSA, 2015). Nevertheless, considering the average BPA concentrations $(0.685$ and $0.892 \mu \mathrm{g} / \mathrm{L}$, respectively for farms A and B) and mean daily milk consumption (200 $\mathrm{mL} / \mathrm{die}$ ), in respect to the medium scenario the consumer might be exposed to higher BPA levels in almost $45 \%$ (farm A) and $36 \%$ (farm B) of samples (Figure 1).

If BPA exposure through milk and dairy products is considered, the age of the consumers is one of the most important factors (Muncke, 2009). It should be considered that BPA also at low-dose may have lasting effects during infant development, and the exposure of a typical Italian consumer may be higher than the reported values because of other contaminated food items. Many studies have reported the effects induced by the exposure to a specific ED, but more attention should be also focused on the potential effects of mixtures of different substances and the synergic effect on human health related to the occurrence of BPA, and other different EDs in milk (EFSA, 2015; Carnevali et al., 2017; Kolatorova et al., 2017).

\section{Farm B: Medium case}

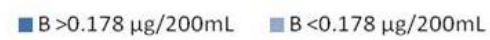

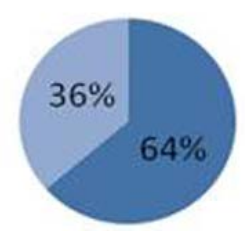

Figure 1. Distribution of contamination levels (\%) in raw milk compared to medium case scenario and mean daily milk consumption.

\section{Conclusions}

The study investigated the occurrence of BPA levels in raw milk at the farm, and BPA dietary exposure, through a hypothetical consumption of raw milk from the cooling tank. BPA has become ubiquitous in the environment as a result of its high production. Global distribution of BPA levels in effluent discharges, surface waters, sewage sludge, sediments, soils, air, and wildlife may influence the contamination of the food chain. As potential contamination pathway of milk chain, environmental sources could have influenced cow's exposure and the excretion of quantifiable levels of BPA in raw milk. The concentrations detected in raw milk from both farms, although slightly lower in milk from farm A, suggest that the geographic area, where the milk was produced, was characterized by low contamination levels. BPA migration from plasticized contact materials during the mechanical milking and the transfer of milk in the cooling tank may have contributed to raw milk contamination, as additional contamination source.

The BPA exposure was below the t-TDI also if the maximum BPA concentration and high daily milk consumption were considered. Nevertheless, the adverse effects of BPA on human health also at low doses, and the synergistic effect of mixtures of BPA and other chemicals should be highlighted. In fact, mixtures of EDs and degradation products of single compounds are frequently involved in the exposure. Therefore, the BPA levels along the milk chain must be routinely monitored, and evaluated from the perspective that milk represents a continuous low-level exposure to different EDs. The application of monitoring programs risk-based and focused on the most relevant chemical hazards in the dairy supply chain might promote food safety.

\section{References}

Bansal A, Henao-Mejia J, Simmons RA, 2018. Immune System: An Emerging Player in Mediating Effects of Endocrine Disruptors on Metabolic Health. Endocrinology 159: 32-45.

Bemrah N, Jean J, Rivière G, Sanaa M, Leconte S, Bachelot $\mathrm{M}$, Deceuninck Y, Le Bizec B, Dauchy X, Roudot AC, Camel V, Grob K, Feidt C, PicardHagen N, Badot PM, Foures F, Leblanc JC, 2014. Assessment of dietary exposure to bisphenol A in the French population with a special focus on risk characterization for pregnant French 
women. Food Che. Toxicol 72: 90-97.

Carnevali O, Notarstefano V, Olivotto I, Graziano M, Gallo P, Di Marco Pisciottano I, Vaccari L, Mandich A, Giorgini E, Maradonna F, 2017. Dietary administration of EDC mixtures: a focus on fish lipid metabolism. Aquat Toxicol 185: 95-104.

Chege P, Ndungu Z, 2016. Analysis of contamination points of milk through the whole value chain process and the quality of milk products in the dairy industry. Avid Science.

Cirillo T, Latini G, Castaldi MA, Dipaola L, Fasano E, Esposito F, Scognamiglio G, Di Francesco F, Cobellis L, 2015. Exposure to di-2-ethylhexyl phthalate, di-n-butyl phthalate and bisphenol A through infant formulas. J Agr Food Chem 63: 3303-3310.

Danaher M, Jordan K, 2013. Identification of existing and emerging chemical residue contamination concerns in milk. Irish J Agr Food Res 52: 173-183.

Diamanti-Kandarakis E, Bourguignon JP, Giudice LC, Hauser R, Prin GS, Soto AM, Zoeller RT, Gore AC, 2009. Endocrine-disrupting chemicals: An Endocrine Society scientific statement. Endocr Rev 30: 293-342.

EFSA, 2015. Scientific Opinion on the risks to public health related to the presence of bisphenol A (BPA) in foodstuffs: Executive summary. EFSA J 13: 39784599.

EPA (US Environmental Protection Agency) 2000. Guidance on information requirements and chemical safety assessment. Chapter 7c: Endpoint Specific Guidance. Version 1.1 European Chemicals Agency: Helsinki.

European Commission, 2011. Regulation of the European Parliament and of the Council of 1 April 2011 amending Regulation (EU) No 10/2011 as regards the restriction of use of Bisphenol A in plastic infant feeding bottles, 321/2011/CE.

European Commission, 2017. Regulation of the European Parliament and of the Council of of 15 March 2017 on official controls and other official activities performed to ensure the application of food and feed law, rules on animal health and welfare, plant health and plant protection products, amending Regulations (EC) No 999/2001, (EC) No 396/2005, (EC) No $1069 / 2009, \quad$ (EC) No 1107/2009, (EU) No 1151/2012, (EU) No 652/2014, (EU) 2016/429 and (EU) 2016/2031 of the European Parliament and of the Council, Council Regulations (EC) No 1/2005 and (EC) No 1099/2009 and
Council Directives 98/58/EC, 1999/74/EC, 2007/43/EC, 2008/119/EC and 2008/120/EC, and repealing Regulations (EC) No 854/2004 and (EC) No $882 / 2004$ of the European Parliament and of the Council,

Council

Directives 89/608/EEC, 89/662/EEC, 90/425/EEC，91/496/EEC，96/23/EC, 96/93/EC and 97/78/EC and Council Decision 92/438/EEC, 2017/625/CE.

European Commission, 2018. Regulation of the European Parliament and of the Council of of 12 February 2018 on the use of bisphenol $\mathrm{A}$ in varnishes and coatings intended to come into contact with food and amending Regulation (EU) No 10/2011 as regards the use of that substance in plastic food contact materials, 2018/213/CE.

Galloway TS, 2015. Micro-and nano-plastics and human health. In Bergmann M, Gutow L, Klages M (eds) Marine anthropogenic litter (pp. 343-366). Springer, Cham.

Georgescu B, Georgescu CE, 2013. Bisphenol A levels in commercial milk, infant formula and dairy products. Anim Biol Anim Husb 5: 171174.

Grumetto L, Gennari O, Montesano D, Ferracane R, Ritieni A, Albrizio S, Barbato F, 2013. Determination of five bisphenols in commercial milk samples by liquid chromatography coupled to fluorescence detection. J Food Protect 76: 1590-1596.

Kolatorova L, Duskova M, Vitku J, Starka L, 2017. Prenatal exposure to Bisphenols and Parabens and impacts on human physiology. Physiol Res 66: S305-S315.

Legler J, Fletcher T, Govarts E, Porta M, Blumberg B, Heindel JJ, Trasande L, 2015. Obesity, diabetes, and associated costs of exposure to endocrine-disrupting chemicals in the European Union. J Clin Endocrinol Metab 100: 1278-1288.

Liu X, Ji Y, Zhang H, Liu M, 2008. Elimination of matrix effects in the determination of bisphenol A in milk by solid-phase microextraction-high-performance liquid chromatography. Food Addit Contam 25: 772-778.

Mercogliano R, Santonicola S, 2018. Investigation on bisphenol A levels in human milk and dairy supply chain: A review. Food Chem Toxicol 114: 98107.

Molina-García L, Fernández-de Córdova ML, Ruiz-Medina A, 2012. Analysis of Bisphenol A in milk by using a multic o m m u t e d f 1 u ori me t r i c sensor. Talanta 96: 195-201.
Muncke J, 2009. Exposure to endocrine disrupting compounds via the food chain: Is packaging a relevant source? Sci Total Environ 407: 4549-4559.

Niu Y, Wang B, Zhao Y, Zhang J, Shao B, 2017. A highly sensitive and highthroughput method for the analysis of bisphenol analogues and their halogenated derivatives in breast milk. J Agr Food Chem 65: 10452-10463.

Piccinelli R, Arcella D, Buonocore P, Capriotti M, D'Addezio L, Le Donne C, Mistura L, Pettinelli A, Sette S, Turrini A, Leclercq C, 2011. L'indagine nazionale sui consumi alimentari in Italia INRAN-SCAI 2005-06. Parte B2 - I consumi in termini di gruppi e sottogruppi alimentari (g/die). Osservatorio Consumi Alimentari, INRAN.

Santonicola S, Albrizio S, Murru N, Ferrante MC, Mercogliano R, 2017(a). Study on the occurrence of polycyclic aromatic hydrocarbons in milk and meat/fish based baby food available in Italy. Chemosphere 184: 467-472.

Santonicola S, De Felice A, Cobellis L, Passariello N, Peluso A, Murru N, Ferrante MC, Mercogliano R, 2017(b). Comparative study on the occurrence of polycyclic aromatic hydrocarbons in breast milk and infant formula and risk assessment. Chemosphere 175: 383390.

Santonicola S, Mercogliano R, 2016. Occurrence and production of furan in commercial foods. Italian $\mathrm{J}$ Food Sci 28: 155-177.

Siddique S, Kubwabo C, Harris SA, 2016. A review of the role of emerging environmental contaminants in the development of breast cancer in women. Emerging Cont 2: 204-219.

Tehrany EA, Desobry S, 2004. Partition coefficients in food/packaging systems: A review. Food Addit Contam 21: 1186-1202.

Tzatzarakis MN, Karzi V, Vakonaki E, Goumenou M, Kavvalakis M, Stivaktakis P, Tsitsimpikou C, Tsakiris I, Rizos AK, Tsatsakis AM, 2017. Bisphenol A in soft drinks and canned foods and data evaluation. Food Addit Contam B 10: 85-90.

van Asselt ED, der Fels $\square$ Klerx HJ, Marvin HJP, Bokhorst $\square$ van de Veen H, Groot MN, 2017. Overview of Food Safety Hazards in the European Dairy Supply Chain. Compr Rev Food Sci F 16: 5975.

Wlodarczyk E, 2015. Occurrence of bisphenol A and its effects on the human body. Arch Physioter Glob Res 19: 13-26. 